\title{
A INFLUÊNCIA DAS VARIAÇÕES TÉRMICAS NOS ACIDENTES LOXOSCÉLICOS EM CURITIBA/PR
}

\author{
Leandro R. Pinto ${ }^{12}$ \\ Francisco Mendonça ${ }^{13}$ \\ Wiviany M. Araujo ${ }^{14}$
}

\begin{abstract}
RESUMO
A cada dia as relações entre ambiente e sociedade trazem novas descobertas. Desde o final da década de 80 , a cidade de Curitiba vem registrando ano a ano um elevado número de acidentes por animais peçonhentos, especialmente acidentes loxoscélicos tornando-se um problema de saúde pública. As aranhasmarrom deste gênero são influenciadas diretamente pelas variações de temperatura, tanto do ponto de vista de sua locomoção como também de sua reprodução. O presente estudo, desenvolvido no campo da Geografia da Saúde, vêm por trazer algumas contribuições para o entendimento da influência da variável temperatura na distribuição temporal (sazonal) dos casos de acidentes loxoscélicos em Curitiba nos anos de 2001 a 2007. Utilizou-se os dados colhidos junto a Secretaria de Saúde, referente ao total de casos por semana epidemiológica para cada ano. Para a análise temporal fez-se uso dos dados metereológicos (temperatura mínima, média e máxima) fornecidos pelo SIMEPAR. O principal resultado encontrado foi a sazonalidade do agravo em relação as variações térmicas anuais e a existência de uma relação direta entre a elevação acima dos $30^{\circ} \mathrm{C}$ das temperaturas e o aumento dos acidentes. Contudo, faz-se necessário levar os resultados obtidos ao conhecimento das autoridades de saúde como forma de auxiliar no controle deste problema.
\end{abstract}

Palavras-chaves: Curitiba/PR, Temperatura do Ar, Aranha-Marrom.

\begin{abstract}
\footnotetext{
12 Geógrafo, Mestrando em Geografia, leandro_geo@pop.com.br

13 Professor, Doutor em Geografia, Chico@ufpr.br

${ }^{14}$ Estudante, Graduanda em Geografia, wivimattozo@gmail.com
}

Every day the relationship between environment and society make new discoveries. Since the end of the 80 , the city of Curitiba has been registering year on year a high number of accidents by venomous animals, especially accidents loxoscélicos (spiders of the genus Loxosceles) become a public health problem. The spiders-brown of this genre are directly influenced by changes in temperature, both from the viewpoint of their locomotion as well as their reproduction. This study, developed in the field of Geography of Health, come by to bring some contributions to the understanding of the influence of variable 
temperature distribution in time (seasonal) of cases of accidents loxoscélicos in Curitiba in the years 2001 to 2007. It was used data collected with the Secretary of Health, referring to the total of cases for epidemiological weeks for each year. For the analysis time has been made use of meteorological data (minimum temperature, average and maximum) provided by SIMEPAR. The main result was found to seasonality of disorder on the annual thermal variations and the existence of a direct relationship between the elevation above $30 \circ \mathrm{C}$ temperatures and the increase in accidents. However, it is necessary to bring the results to the attention of health authorities as a way of helping to control this problem of health in Curitiba.

Key-words: Curitiba/PR, Air Temperature, Brown Spider

\section{INTRODUÇÃO}

O homem sempre se preocupou em tentar entender o processo saúdedoença bem como seus fatores determinantes relacionados. Os estudos referentes ao envolvimento dos fatores socioambientais com o aparecimento, evolução, expansão e distribuição de algumas doenças já é antigo, desde os tempos de Hipócrates em 480 a.C. (LEMOS \& LIMA, 2002, p. 75) com seu ensaio "Dos ares, das águas e dos lugares", onde o autor faz um traçado sobre a influência do meio sobre o organismo humano. Na atualidade, pode-se destacar que os ramos da Medicina preocupam-se com a perspectiva do indivíduo, ou seja, o corpo como objeto do processo saúde-doença, já os ramos da Epidemiologia e Geografia da Saúde preocupam-se em estudar os processos ocorridos no coletivo, ou seja, a sociedade é o foco das pesquisas em saúde e doença.

Esta perspectiva de saúde e doença está diretamente relacionada a própria relação sociedade e natureza, pois na medida em que o ser humano constrói novas paisagens (rurais, urbanas, etc.) surgem as doenças reemergentes e, por conseqüência, novas formas de obtenção da plena saúde.

É neste enfoque que o presente trabalho é desenvolvido, visando analisar a influência dos fatores climáticos, em especial a temperatura, na distribuição sazonal dos casos de Acidentes Loxoscélicos ${ }^{15}$ em Curitiba/PR (Figura 01), tomando como base os ataques ocorridos entre os anos de 2001 e 2007.

Tal trabalho se justifica pois desde o final da década de 80 a cidade de Curitiba vem registrando ano a ano um elevado número de acidentes por animais peçonhentos, mais especialmente acidentes por aranhas do gênero Loxosceles. Em 2006 a Secretaria de Estado da Saúde registrou 5.325 casos de picadas em todo o Paraná e o maior número de casos foi, como se era esperado, registrado em Curitiba somando 2.480 acidentes, além disso sabe-se que o comportamento dessas aranhas responde diretamente as variações da temperatura do ar, o que influencia em sua dinâmica e por conseguinte no número de picadas.

15 Entende-se Acidentes Loxoscélicos pela picada das aranhas do gênero Loxosceles, ou popularmente conhecida "aranha-marrom". 
Neste contexto, o objetivo geral desta pesquisa é verificar e analisar como as variações da temperatura do ar influenciaram nos Acidentes Loxoscélicos no Município de Curitiba/PR no período de 2001 e 2007.

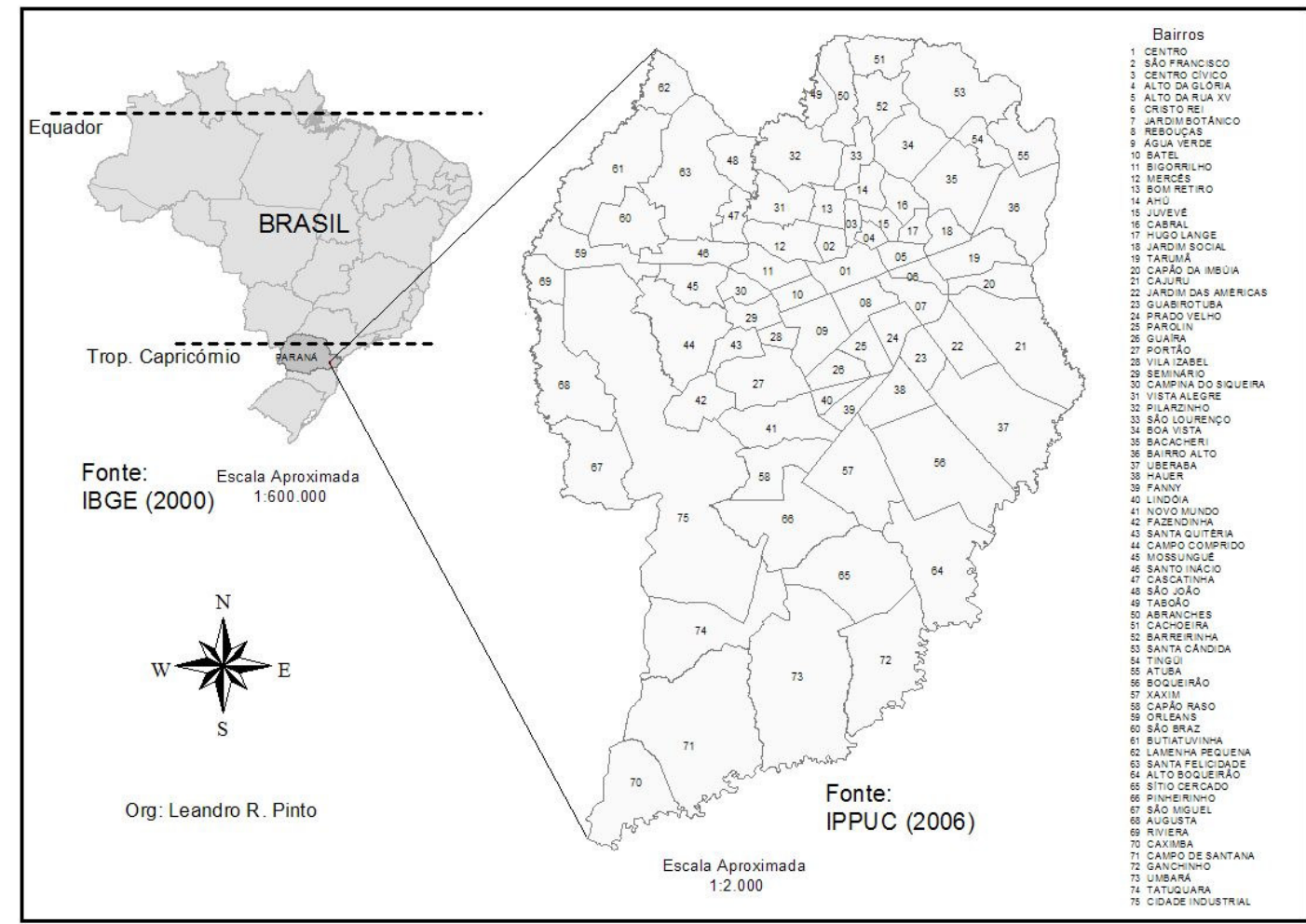

Figura 01. Localização da Área de Estudo: Município de Curitiba (Paraná-Brasil)

\section{MATERIAIS E MÉTODOS}

A metodologia utilizada baseia-se na concepção de Multicausalidade (NATAL, D. 2004) que preconiza que a doença não é conseqüência exclusiva da ação de um único agente, mas que fatores interagem para que ela se manifeste. Qualquer ruptura do sistema composto pelo agente (neste caso as aranhas do gênero Loxosceles), o homem (a sociedade curitibana como um todo) e o ambiente (temperatura do ar em Curitiba), ou sua desestabilização, geraria um estado de doença (acidentes loxoscélicos). Com relação aos procedimentos pode-se citar as seguintes etapas:

A primeira etapa da pesquisa caracteriza-se pela fundamentação teórica do objeto do estudo. Visando o aprofundamento da formação de uma base teórico-metodológica foram levantados os assuntos referentes a ecologia das aranhas do gênero Loxosceles e suas características comportamentais. No que se refere a Curitiba tomou-se como base estudar seu clima e algumas características socioeconômicas atuais da cidade.

A segunda etapa caracterizou-se pela coleta dos dados. Para o estudo dos acidentes loxoscélicos na escala abordada, foram coletados junto a 
Secretaria Municipal de Saúde de Curitiba informações no sistema SINAN referentes aos casos confirmados de acidentes loxoscélicos em Curitiba para o período de 2001 a 2007. Esses dados foram organizados em séries temporais conforme a Semana Epidemiológica ${ }^{16}$ do caso.

Os dados metereológicos foram coletados junto a estação de Curitiba do Instituto Tecnológico SIMEPAR através de pedidos oficiais a essa instituição. Foram coletados dados diários de temperatura mínima, temperatura média e temperatura máxima, umidade relativa do ar e precipitação para o período de janeiro de 2001 a dezembro de 2007. Tais variáveis foram adotadas pois são as mais significantes nas condições de vida das aranhas do gênero Loxosceles, assim influenciando diretamente nos seus hábitos, sua circulação pelos domicílios e consequentemente nos acidentes loxoscélicos. A abordagem climática da presente pesquisa envolve a concepção sistêmica, na qual a manifestação dos elementos climáticos constitui a saída do sistema clima, sendo os casos de acidentes Loxoscélicos influenciada por este sistema.

Os dados de saúde e metereológicos supramencionados foram tratados estatisticamente com software Microsoft Excel 2003 e depois organizados em bancos de dados. O tratamento dos dados e a confecção de gráficos e tabelas abrangem a terceira etapa da pesquisa.

A quarta etapa corresponde ao estabelecimento das relações e correlações entre as características da temperatura do ar curitibana e a manifestação dos acidentes Loxoscélicos. Na escala local tal relação foi analisada temporalmente por semana epidemiológica e/ou mensalmente. Com isso pode-se chegar a significativos resultados referentes ao trabalho desenvolvido.

\section{RESULTADOS E DISCUSSÕES}

Curitiba está localizada entre as latitudes $25^{\circ} 20^{\prime}$ e $25^{\circ} 38^{\prime}$ Sul e longitude entre $049^{\circ} 11^{\prime}$ e $049^{\circ} 23^{\prime}$ Oeste, a uma altitude média de 934 metros sobre o nível do mar. Tais elementos auxiliam na caracterização do clima curitibano, ou seja, a latitude que define a intensidade da radiação solar que um dado lugar recebe e a altitude no que condiz ao gradiente térmico vertical.

Do ponto de vista da classificação climática, Curitiba apresenta um tipo subtropical úmido segundo a classificação de Strahler, temperado quente sempre úmido $(\mathrm{Cfb})$ conforme a classificação de Koppen ou também clima tipo Mesotérmico Brando - superúmido - sem seca, segundo a classificação do IBGE. (NOGAROLLI, M. 2007).

Dentre as características climáticas principais de Curitiba podemos destacar as chuvas, distribuídas de maneira não uniforme durante o ano, e as temperaturas fortemente marcadas pela sazonalidade. Segundo DANNIOLIVEIRA (1999) "[...] o verão curitibano constitui-se no período mais chuvoso, enquanto que o inverno se apresenta como o mais seco.". Para a autora, os

\footnotetext{
${ }^{16}$ Em todo âmbito do Sistema de Saúde do Brasil, utiliza-se de critério uniforme de identificação das semanas epidemiológicas do ano, para efeito de registro, tabulação e apresentação de dados estatísticos quer técnicos, quer administrativos. Por convenção internacional as semanas epidemiológicas são contadas de domingo a sábado. A primeira semana do ano é aquela que contém o maior número de dias de janeiro e a última a que contém o maior número de dias de dezembro. Poe exemplo, para o ano de 2004 a semana 01 inicia-se no dia 04/01/2004 e a semana 52 encerrase no 01/01/2005. Para o ano de 2005 a semana 01 inicia-se no dia 02/01/2005 e a semana 52 encerra-se no 31/12/2005.
} 
períodos mais secos caracterizam-se por chuvas variando entre 70 a $100 \mathrm{~mm}$ por mês, enquanto que nos períodos mais chuvosos esses valores sobem para os 130 a $180 \mathrm{~mm}$. A sazonalidade térmica e pluviométrica evidencia a característica subtropical do clima curitibano.

Para Mendonça (2001) as principais características do clima curitibano são: mesotérmico, subtropical úmido com verões frescos, sem estação seca e com ocorrência de geadas severas demasiado freqüentes. Sobre a questão térmica o mesmo autor (ibid.) cita a característica curitibana de uma considerável amplitude térmica e diária, ainda ressalta

\begin{abstract}
Que embora considerada como de verão tipicamente fresco, a tropicalidade climática de Curitiba é evidenciada em momentos precisos, tais como a elevação das temperaturas entre novembro e março com médias próximas de $20^{\circ} \mathrm{C}[\ldots]$. O inverno, entretanto realça a característica particular do clima regional, cujas temperaturas são bastante baixas para os padrões tropicais; junho e julho são considerados como os meses mais frios do ano, nos quais a temperatura média pode chegar aos $13^{\circ} \mathrm{C}[\ldots]$. (MENDONÇA, 2001, p. 130).
\end{abstract}

Um grande fator a se destacar no clima curitibano é o fato da variabilidade de fenômenos que acontecem num espaço de tempo teoricamente curto. Este fato é ressaltado nas palavras de MENDONÇA (2001) ao falar que "a atmosfera curitibana registra comumente [...] a ocorrência de variados tipos de tempo num só dia ou estação, dando a impressão de se vivenciar as quatro estações do ano num mesmo dia ou mês". Outros fatos importantes que podem se destacar em relação as características climáticas curitibanas são: as baixas temperaturas médias anuais (caracterizado pela subtropicalidade e altitude da cidade), as freqüentes inundações em áreas de risco causadas pelas altas precipitações nos meses de verão, as características climáticas de aglomerações urbanas geradas pelos processos de poluição e urbanização, etc.

Contudo, as características climáticas de Curitiba estão diretamente ligadas as condições de variações de temperatura, umidade, pressão, etc., influenciando assim a sociedade ali residente assim como os animais que residem no ambiente urbano, no caso deste trabalho as aranhas do gênero Loxosceles também sofrem influencias diretas da variações meteorológicas, o que influi em seu comportamento e consequentemente no número de Acidentes Loxoscélicos.

O município de Curitiba apresenta apenas duas espécies de aranhas do gênero Loxosceles (Figura 02): L. laeta e $L$. intermédia com freqüência média de $10 \%$ para a $L$. Laeta e $90 \%$ para $L$. intermedia. FISCHER (2002) demonstra que a ampla distribuição da L.intermedia está relacionada com a especificidade do hábito e do habitat. L.intermedia é mais generalista do que L. laeta em vários aspectos ecológicos, ocupando desta forma os espaços vazios, obtendo sucesso na colonização de outros locais com condições ambientais favoráveis.

O alto grau de infestação de L. intermedia (estimado em 97\% das residências) intra e/ou peridomiciliarmente encontrado por FISCHER (1994, 2002) estão relacionados ao comportamento mais ativo (com maior mobilidade) e hábito generalista (menos exigente em relação aos fatores ambientais) desta espécie proporcionando maior contato com a população humana. Entretanto este aspecto comportamental difere das observações para $L$. laeta que apresenta maior especificidade pelo ambiente e maior permanência no substrato 
preferencial ${ }^{17}$. Tal característica parece favorecer um baixo índice de acidentes mesmo em locais com alta infestação desta espécie (BUCHERL, W. 1961; FISCHER, M. 2002).

Figura 02. Aranha-Marrom (Loxosceles Heinecken \& Lowe, 1832) Fonte: TRENTINI (2005)

No município, L. Laeta e L. intermédia são encontradas associadas a construções antrópicas, sendo rara sua presença na natureza. Porém, tem-se registros da espécie $L$. laeta encontradas em árvores exóticas como 0 Eucalyptus sp., uma árvore que apresenta longas cascas desprendidas, fendas e ocos, que constituem ambientes favoráveis. (FISCHER, M. 2002). O hábito sinantrópico ${ }^{18}$ do gênero está relacionado com a semelhança entre os substratos presentes nas habitações e o seu habitat natural e todas suas espécies estão aptas a aceitarem o habitat doméstico, caso ele esteja disponível. (GERTSCH, W. 1967).

Em Curitiba a população da aranha-marrom das espécies $L$. intermédia e L.laeta é muito superior à média de outras regiões e, consequentemente, o número de acidentes loxoscélicos, que vêm crescendo ano a ano, com uma leve acentuada nos últimos 3 anos conforme pode ser observado na Figura 03. Mesmo assim, Curitiba supera em muito a média nacional, levando as autoridades a tomarem medidas diversas para combater o problema, considerado de ordem epidemiológica. (VETORELLO, M. 2002).

Para a capital paranaense, VETORELLO (2002) afirma: "o acidente loxoscélico é um agravo de destacada importância no município de Curitiba, pois apresenta anualmente cerca de 2000 casos de acidentes ocasionados por aranhas do gênero Loxosceles". Os acidentes têm, dentre suas causas, alguns fatores essências como o grande e crescente número de aranhas, a falta de predadores naturais, devido principalmente ao grande e desordenado processo

\footnotetext{
17 Por Substrato Preferencial entende-se como sendo a melhor camada dos domicílios onde as aranhas encontram abrigo e alimento para a sobrevivência e reprodução.

${ }^{18}$ Animais que convivem com o homem, mas não são domésticos.
} 
de urbanização de Curitiba, e, os fatores climáticos, que como VETORELLO (Ibid.) cita: "[...] mudanças climáticas, com diminuição da duração e intensidade dos períodos de frio na cidade podem, também, ter ocasionado o aumento do número de acidentes". Já para TRENTINI (2002), "os acidentes ocorrem nos meses mais quentes do ano, principalmente entre os meses de setembro e maio e ocorrem no interior das moradias ou em seu peridomicílio, alojando-se em locais quentes e secos $[\ldots]^{\prime \prime}$.

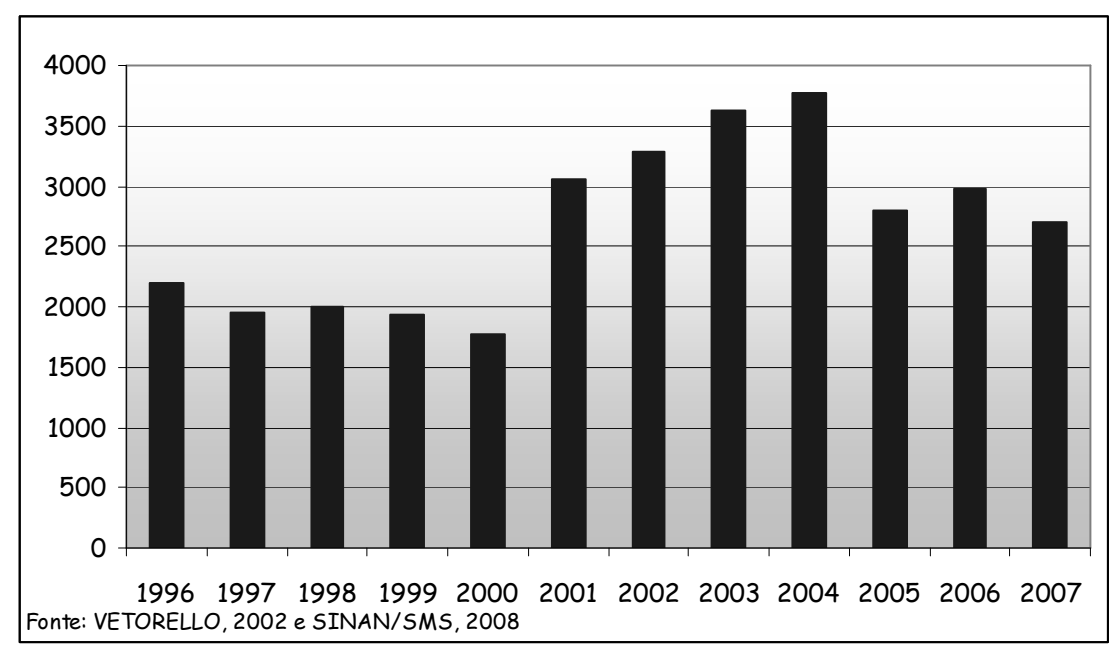

Figura 03. Acidentes Loxoscélicos em Curitiba/PR, período de 1996 a 2007

Como já exposto, os Acidentes Loxoscélicos são causados por aranhas do gênero Loxosceles e como tal, respondem diretamente as suas manifestações biológicas que frequentemente são reguladas conforme as variações climáticas. Outro fato já exposto também é que em Curitiba, a variação dos elementos climáticos durante o ano é bem visível, respondendo diretamente à sazonalidade imposta pelas estações do ano.

O estudo da distribuição temporal de uma doença através das variáveis climáticas é de grande validade visto a influência exercida pelo clima como afirma MENDONÇA (2000) "Os impactos do clima sobre a sociedade repercutem, dentre outros, na condição de saúde humana [...]", e porque não dizer nas condições de vida de animais como as aranhas.

A evolução dos Acidentes Loxoscélicos em Curitiba para o período analisado, ou seja, entre 2001 e 2007, apresentou-se nas distribuições anuais de forma crescente se tomar em conta o período entre 2001 (que apresentou 3061 casos) a 2004 (com cerca de 3773 casos), e após tivemos um leve declínio para o ano de 2005 (2798 casos), um aumento para o ano de 2006 (com 2972) e novamente uma queda para o ano 2007 (2705 casos), que demonstra previamente para o período de 2005 a 2007 uma certa estabilidade na freqüência dos casos. Tal fato pode ser observado na Figura 04.

Quanto a variação mensal dos Acidentes Loxoscélicos, pode-se observar que os mesmos respondem diretamente a variação das estações de ano, ou seja, conforme a variação anual das temperaturas. Nos meses mais quentes de final de primavera (outubro e novembro) e de verão (dezembro a março) em Curitiba os Acidentes Loxoscélicos tem seu pico mais elevado no número de casos, com uma queda significativa a partir de abril (início de outono) chegando ao declínio máximo entre os meses de junho e julho, ou seja, nos meses mais 
frios de inverno, com a elevação das temperaturas novamente a partir de setembro e outubro, elevam-se novamente os casos. Tal fato pode ser observado, ano a ano, para o período analisado na Figura 05.

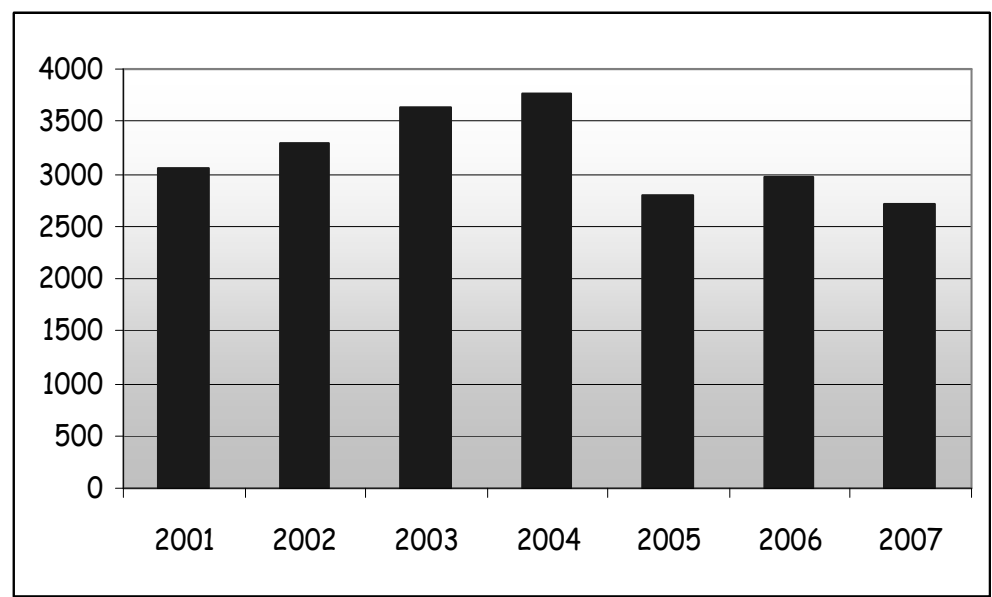

Figura 04. Variação Anual dos Acidentes Loxoscélicos em Curitiba/PR (2001 2007)

Fonte: SMS/Curitiba (2008)

Para evidenciar a relação entre as variáveis climáticas como a temperatura do ar e os Acidentes Loxoscélicos tomou-se como base a interpretação gráfica de tal relação. Para tanto optou-se por verificar a validez das variáveis: temperatura do ar (mínima, média e máxima). Umidade relativa do ar e precipitação total. Tais elementos mais os casos de Acidentes Loxoscélicos foram agrupados de forma mensal para o período analisado (2001 - 2007) e, dispostos de forma única, um sobre o outro, para uma melhor análise mensal da correlação existente entre eles. Tal fato pode ser observado na Figura 06.

Analisando o Gráfico é possível comprar a hipótese já lançada que a variação dos Acidentes Loxoscélicos responde diretamente a variação das temperaturas. Vê-se que os maiores picos dos casos estão diretamente ligados aos meses mais quentes do ano, em especial aos superiores a $30^{\circ} \mathrm{C}$. As temperaturas de Curitiba, e consequentemente os Acidentes Loxoscélicos, apresentam ciclos de altas e baixas, diretamente ligados as estações do ano em Curitiba.

Quanto a precipitação também é visível a sua relação direta com as temperaturas, tendo em vista que nos meses mais quentes de Curitiba foram registrados as maiores concentrações de precipitação total, em especial ao meses de janeiro e fevereiro que na maior parte do anos registrou um total mensal superior a $200 \mathrm{~mm}$. Na bibliografia consulta acerca das aranhas, não se vê nenhuma relação direta do comportamento das Loxosceles com relação a precipitação, pois as mesmas encontram-se na maioria das vezes, para Curitiba, dentro dos domicílios, ou seja, em abrigos. Mas a relação a ser feita é da interferência das chuvas na própria variação diária e mensal das temperaturas, aí sim relacionado diretamente a variação dos Acidentes Loxoscélicos.

Em relação a umidade relativa do ar, Curitiba apresentou para o período analisado uma variação média entre $60 \%$ e $90 \%$, ou seja, em nenhum mês tivemos casos extremos de baixa umidade, que poderia ser visto somente numa 
análise diária. Com relação ao Acidentes Loxoscélicos, a bibliografia consultada fala que condições normais de vida para as Loxosceles em Curitiba devem estar na média de $70 \%$ com margem de $10 \%$ para mais ou para menos (FISCHER, 2002), ou seja, para o período analisado a umidade apresentou-se de forma normal as condições de vida. Por isso não se vê, relação direta entre a umidade relativa e os casos de Acidentes Loxoscélicos, reforçando o que já havia sido exposto por Vetorello (2001) para o período entre 1998 e 2001.

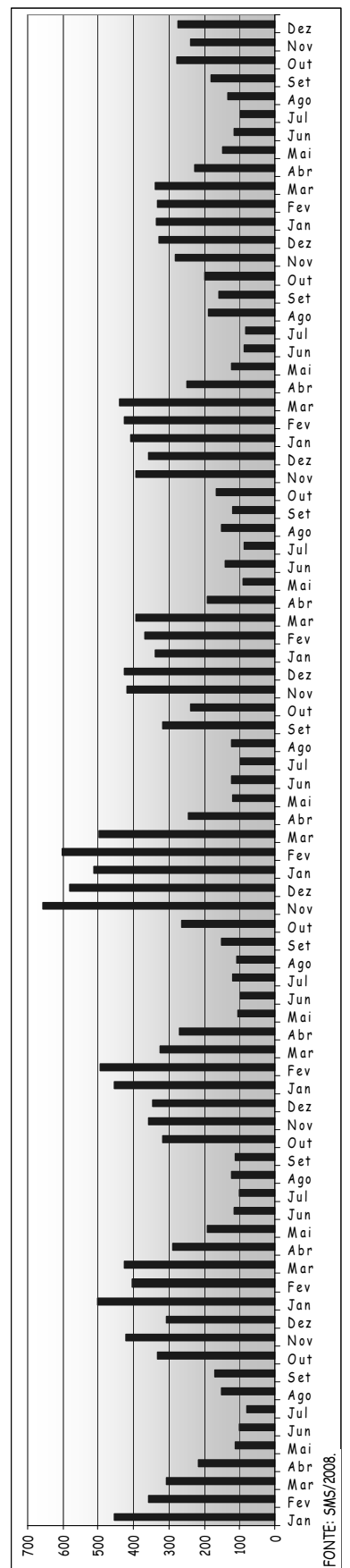

Figura 05.Variação Mensal dos Acidentes Loxoscélicos em Curitiba (2001-2007) 

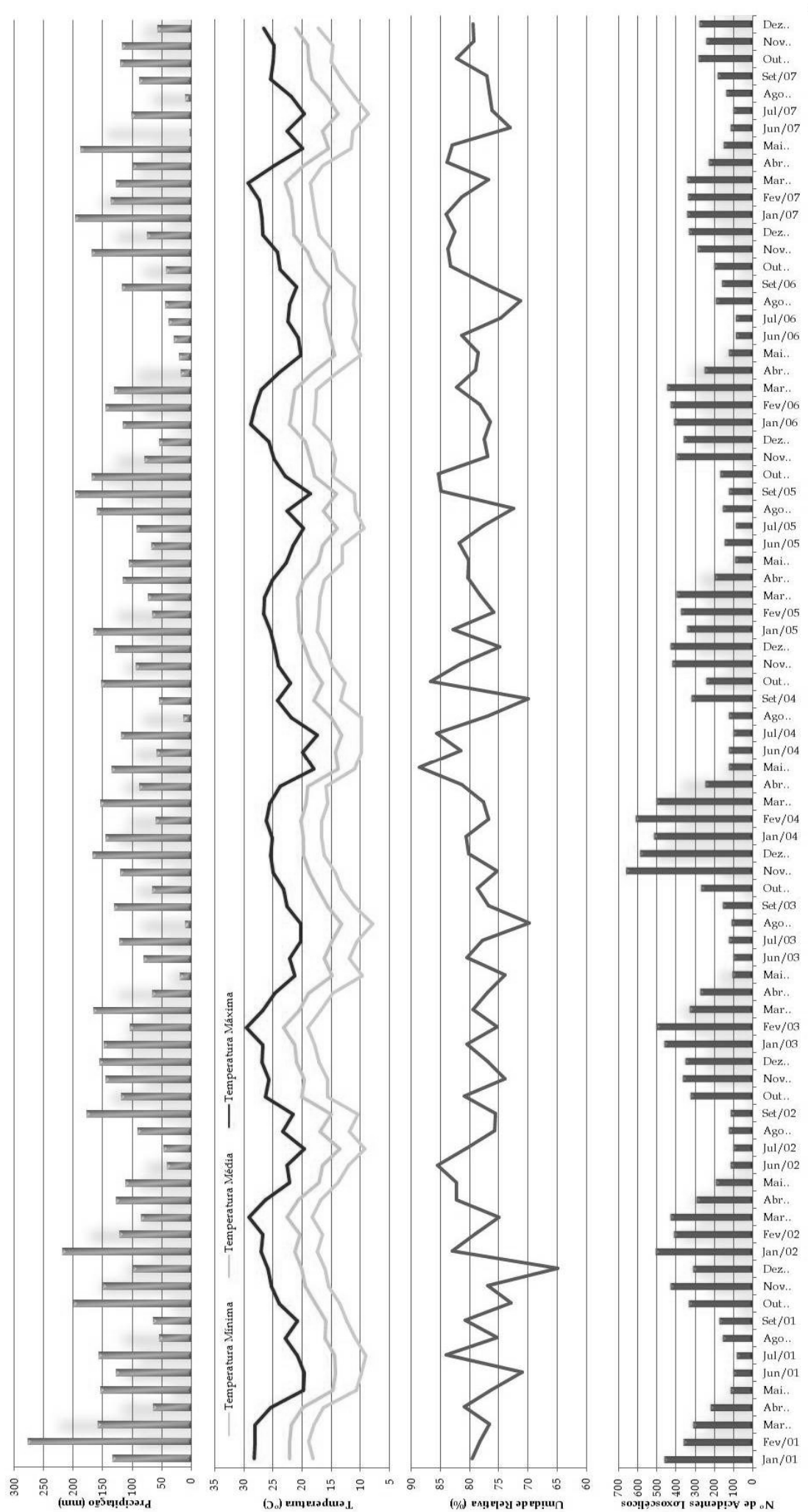

Figura 06. Curitiba/PR - Variáveis Climáticas e Casos de Acidentes Loxoscélicos (2001-2007) 
Como já exposto as aranhas em geral são influenciadas diretamente pela variação da temperatura do ar ao longo do ano, dos meses e em alguns casos, como as aranhas do gênero Loxosceles, as próprias variações térmicas que acontecem ao longo de um dia. Tal variação também é fator limitante da distribuição das aranhas em todo o globo, fato dado, pois muitos desses animais têm limites de temperatura (positivos e negativos) considerados letais para os mesmos.

Em estudos experimentais Fischer e Vasconcellos-Neto (2003) determinaram as temperaturas máximas e mínimais letais para as aranhas $L$. intermedia e L. laeta (únicas deste gênero presentes em Curitiba). Os pesquisadores conseguiram estabelecer que a temperatura máxima letal em média para aranhas citadas é de $40^{\circ} \mathrm{C}$, ou seja, este é o limite suportado antes que os indivíduos venham a óbito, sendo que quanto mais próximo as aranhas se encontrem desta temperatura as mesmas tendem a se locomover para eliminar o risco, procurando assim outro ambiente mais ameno.

Outro dado importante para esta análise é referente ao projeto "PRONEX - Monitoramento e controle populacional da aranha-marrom (loxosceles Intermedia): semioquímicos, limonóides de meliáceas e predadores naturais" vigente na atualidade e que visa encontrar novas formas de controle da aranhamarrom através do uso de inseticidas, repelentes, animais predadores, etc. Em estudos iniciais, este grupo encontrou na casa teste para o projeto ${ }^{19}$ a presença maciça de aranhas localizadas no ático desta residência, enquanto que nos cômodos normais sua presença era bem menor e restrita a frestas de madeira, atrás de móveis, etc., demonstrando uma preferência das aranhas por este substrato. Outro dado importante encontrado através de sensores térmicos é uma diferença de temperatura entre o ático da residência e o seu interior de até $10^{\circ} \mathrm{C}$ dependendo do dia, ou seja, demonstrando que a maior presença das aranhas no ático está relacionada também a maior temperatura encontrada neste local da residência.

A partir desses dados toma-se o seguinte raciocínio para o prosseguimento desta análise: As aranhas L. intermedia e L. laeta tem uma temperatura máxima letal em média de $40^{\circ} \mathrm{C}$, ou seja, antes disso as mesmas tendem a procurar locais de menor temperatura, se essas aranhas, em especial a L. intermedia, tem preferência por habitar o ático das residências pelas condições já dadas e esses áticos podem apresentar uma diferença térmica de até $10^{\circ} \mathrm{C}$ em relação ao interior ou até mesmo a temperatura externa (ambiente), entende-se que a partir de uma temperatura ambiente do ar de $30^{\circ} \mathrm{C}$ as aranhas localizadas nesses áticos tendem a se locomover para ambientes mais frios para sua sobrevivência, assim sendo, as mesmas deslocam-se para o interior dos domicílios, em especial para o substrato abaixo do ático, ou seja, para os quartos, sala, banheiro, etc. podendo assim ter o encontro com o ser humano e conseqüentemente ocorrer os Acidente Loxoscélicos.

Apresentada essa hipótese, passou então a verificar os dados para validar ou refutar tal raciocínio. Para isso, utilizou-se basicamente de duas variáveis: a temperatura do ar máxima diária e o total de Acidentes Loxoscélicos por semana epidemiológica. Selecionou-se todos os dias onde a temperatura do ar máxima ultrapassou a casa dos $30^{\circ} \mathrm{C}$ e comparou-se com o número de casos

\footnotetext{
19 Domicílio localizado dentro do Centro de Pesquisas e Produção de Imunobiologia - CPPI, da Secretaria Estadual de Saúde do Paraná, no município de Piraquara/PR.
} 
ocorridos na semana epidemiológica anterior a elevação desta temperatura, a semana da ocorrência da elevação bem como da semana seguinte para ver se houve significativa mudança nos dados. O resultado pode ser visualizado na Tabela 01 que se segue.

Tabela 01. Temperaturas acima de $30^{\circ} \mathrm{C}$ e Acidentes Loxoscélicos (2001 2007)

\begin{tabular}{|c|c|c|c|c|c|}
\hline Ano & Mês & $\begin{array}{c}\text { Dias com Temperatura } \\
\text { Acima de } 30^{\circ} \mathrm{C}\end{array}$ & $\begin{array}{c}\mathrm{N}^{\circ} \mathrm{de} \\
\text { Casos na } \\
\text { Semana } \\
\text { Anterior }\end{array}$ & $\begin{array}{c}N^{\circ} \text { de } \\
\text { Casos na } \\
\text { Semana }\end{array}$ & $\begin{array}{c}N^{\circ} \text { de Casos na } \\
\text { Semana } \\
\text { Seguinte }\end{array}$ \\
\hline \multirow{9}{*}{2001} & Janeiro & $7,8,9$ & 63 & 97 & 85 \\
\hline & & $16,17,18,19$ & 97 & 85 & 84 \\
\hline & & $27,28,29$ & 84 & 127 & 93 \\
\hline & Fevereiro & $14,15,16$ & 93 & 97 & 95 \\
\hline & & $22,23,24,25$ & 97 & 95 & 71 \\
\hline & Setembro & 2,4 & 44 & 72 & 44 \\
\hline & Novembro & 6,7 & 106 & 119 & 81 \\
\hline & & 23,24 & 81 & 98 & 124 \\
\hline & Dezembro & $19,20,21$ & 87 & 89 & 46 \\
\hline & & & & & \\
\hline \multirow{7}{*}{2002} & Janeiro & $21,26,27$ & 66 & 105 & 118 \\
\hline & & $5,8,9$ & 96 & 112 & 133 \\
\hline & Março & $10,11,12,13,15,16$ & 112 & 133 & 98 \\
\hline & & $17,18,20$ & 133 & 98 & 82 \\
\hline & & $26,29,30,31$ & 98 & 82 & 83 \\
\hline & Outubro & $6,7,8,9,10,11$ & 52 & 91 & 59 \\
\hline & Dezembro & $28,29,30,31$ & 75 & 60 & 106 \\
\hline \multirow{6}{*}{2003} & & & & & \\
\hline & Janeiro & $6,7,9,10$ & 60 & 106 & 95 \\
\hline & Fevereiro & $2,3,4,7,8,9$ & 81 & 128 & 153 \\
\hline & & $24,25,26,27,28,01 / 03$ & 86 & 128 & 95 \\
\hline & Setembro & 22,23 & 29 & 70 & 46 \\
\hline & Novembro & $10,11,12$ & 65 & 232 & 172 \\
\hline & & & & & \\
\hline \multirow{4}{*}{2004} & Fevereiro & 3,4 & 149 & 197 & 113 \\
\hline & Março & 8,10 & 132 & 118 & 80 \\
\hline & Setembro & $6,7,8,9$ & 45 & 78 & 34 \\
\hline & Dezembro & 30,31 & 71 & 65 & 78 \\
\hline & & & & & \\
\hline \multirow{6}{*}{2005} & Janeiro & $8,9,10,15$ & 78 & 99 & 64 \\
\hline & Fevereiro & $19,22,23$ & 89 & 112 & 70 \\
\hline & Março & $8,9,11,12$ & 70 & 97 & 83 \\
\hline & Outubro & 12,13 & 29 & 55 & 38 \\
\hline & Novembro & 15,16 & 46 & 107 & 91 \\
\hline & Dezembro & $22,23,24$ & 80 & 113 & 76 \\
\hline & & & & & \\
\hline \multirow{7}{*}{2006} & Janeiro & $6,7,8,9,10$ & 90 & 103 & 124 \\
\hline & & $13,14,15,16$ & 103 & 124 & 90 \\
\hline & Fevereiro & $3,4,5$ & 90 & 123 & 120 \\
\hline & Março & $2,3,4,7,8$ & 105 & 112 & 83 \\
\hline & Setembro & $12,13,14,15$ & 20 & 74 & 36 \\
\hline & Novembro & $16,17,24$ & 47 & 53 & 65 \\
\hline & Dezembro & $15,16,17,18,19$ & 88 & 94 & 71 \\
\hline & & & & & \\
\hline \multirow{7}{*}{2007} & Janeiro & 25,27 & 70 & 53 & 72 \\
\hline & Fevereiro & $23,24,25$ & 54 & 104 & 99 \\
\hline & Março & $5,6,7,8,9,10$ & 99 & 97 & 99 \\
\hline & & $24,25,26,27,28,29,30,31$ & 52 & 91 & 41 \\
\hline & Outubro & 10,12 & 35 & 52 & 54 \\
\hline & Dezembro & $2,3,4$ & 66 & 90 & 76 \\
\hline & & $28,29,30,31$ & 58 & 49 & 61 \\
\hline
\end{tabular}

Fonte: Secretaria Municipal de Saúde (2008) / Simepar (2008)

Org.:PINTO (2009) 
Em geral, a cidade de Curitiba não apresenta muitos dias do ano com temperaturas máximas superiores a $30^{\circ} \mathrm{C}$, normalmente tais temperaturas foram alcançadas para o período analisado nos meses de janeiro, fevereiro, novembro e dezembro com alguns casos esporádicos nos meses de março, setembro e outubro. Isso se dá devido as características climáticas de Curitiba, mas basicamente se deve a subtropicalidade da cidade aliada a altitude local, dentre outros fatores. Os anos de maior destaque foram 2002, 2006 e 2007 com mais de 27 dias com temperaturas superiores a casa dos $30^{\circ} \mathrm{C}$, enquanto que o ano de 2004 apresentou apenas 10 dias durante todo o ano com temperaturas acima dessa marca.

Sobre a observação dos dias superiores a $30^{\circ} \mathrm{C}$ e os casos de Acidentes Loxoscélicos tem-se como resultado que a análise referente a semana anterior as altas temperaturas, semana dos dias de $30^{\circ} \mathrm{C}$ e a semana posterior ao aumento teve-se um total de 45 conjuntos de semanas analisadas. Deste total, teve-se o seguinte resultado: $11 \%$ dos conjuntos analisados tiveram o maior número de casos na semana epidemiológica anterior aos dias com máximas de $30^{\circ} \mathrm{C}, 20 \%$ ocorreram na semana posterior aos picos de temperatura e $69 \%$ dos conjuntos estudados tiveram o maior número de Acidentes Loxoscélicos na mesma semana epidemiológica dos dias com temperaturas acima de $30^{\circ} \mathrm{C}$. Isto valida a hipótese apresentada, ou seja, nos dias em que a temperatura máxima do ar ultrapassou os $30^{\circ} \mathrm{C}$ as aranhas localizadas nos áticos ou locais mais quentes dos domicílios tendem a se locomover para outras regiões das casas, ao se deslocarem tem a possibilidade do encontro com seres humanos o que pode levar ao Acidente Loxoscélico.

Em geral, o tempo entre a possível picada da aranha até o acidentado ser atendido em uma Unidade de Saúde de Curitiba não ultrapassa a casa das 48 horas ( 2 dias), sendo assim pode-se entender que o registro dos casos tendem a ser na mesma semana epidemiológica em que ocorreram as altas temperaturas de $30^{\circ} \mathrm{C}$, a não ser quando essa elevação ocorresse nos últimos dois dias da semana epidemiológica, entrando assim para o total de casos da próxima semana. Isto é válido na medida em que $89 \%$ dos conjuntos analisados apresentaram o maior número de casos na semana das altas temperaturas ou na posterior, e mesmo dos outros $11 \%$ restantes onde o maior número de Acidentes Loxoscélicos ocorreu na semana anterior as temperaturas de $30^{\circ} \mathrm{C}$ cerca de metade corresponde a conjuntos em que a semana das altas temperaturas é sucessiva de outra semana de alta, ou seja, a queda dos casos se deu pois na semana anterior houve maior número de dias com altas temperaturas do que a semana analisada.

Com isso, entende-se que a variável ambiental da temperatura do ar é influente na questão dos Acidentes Loxoscélicos em Curitiba, em especial no que concernem as temperaturas superiores a $30^{\circ} \mathrm{C}$, que podem ser letais para as aranhas do gênero Loxosceles que habitam na cidade, influenciando assim na questão social, pois as mesmas tendem a ter o encontro com os seres humanos, gerando assim um estado de alerta na sociedade, passível dos Acidentes Loxoscélicos.

\section{CONCLUSÕES}

Ao se estudar todo a complexa relação existente entre o ambiente, neste caso representado pelas variações climáticas, e uma determinada doença ou 
agravo como são os Acidentes Loxoscélicos, deve-se valorizar cada pequeno detalhe, pois as próprias variações no número de casos respondem diretamente as pequenas variações diárias de temperatura do ar.

As características climáticas curitibanas, típicas de sub-tropicalidade, caracterizam fortemente a sazonalidade das variações de temperatura e precipitação. Tais variações influenciam diretamente na condição de vida da sociedade e dos animais que habitam a capital paranaense.

Assim sendo, pode-se observar que as aranhas do gênero Loxosceles respondem diretamente as variações da temperatura do ar em especial as superiores a $30^{\circ} \mathrm{C}$ e, consequentemente, os Acidentes Loxoscélicos sofrem a variação sazonal climática.

Porém, não pode-se cair no determinismo de que somente o clima é responsável pelo variação dos Acidentes, pois sabe-se que fatores sociais e populacionais também influenciam na distribuição espacial e temporal dos casos.

Concluindo, a expansão urbana de Curitiba modificou as características de vida das aranhas tornando-as sinantrópicas, e o desconhecimento da população aliado a moradias que favorecem a instalação e proliferação das mesmas, bem como a ausência de predadores naturais, e as condições climáticas curitibanas com características de subtropicalidade influenciam na dinâmica da aranha-marrom, conseqüentemente, no número de Acidentes Loxoscélicos.

Por fim, a necessidade de um estudo na avaliação dos fatores climáticos que estariam favorecendo a infestação e, por conseguinte, os casos de acidentes loxoscélicos, vêm a contribuir muito para o entendimento da dinâmica da aranha-marrom no município de Curitiba.

\section{AGRADECIMENTOS}

Ao SIMEPAR pelo fornecimento dos dados metereológicos e a Secretaria Municipal de Saúde de Curitiba pelos dados de saúde utilizados nesta pesquisa.

\section{REFERÊNCIAS}

BUCHERL, W. Aranhas do gênero Loxosceles e Loxoscelismo na América. In: Memórias do Instituto Butantã. São Paulo, vol. 13, n.o 14, 1961. p.213 224.

DANNI-OLIVEIRA, I. M. A cidade de Curitiba/PR e a poluição do ar. Implicações de seus atributos urbanos e geoecológicos na dispersão de poluentes em período de inverno. Tese de Doutorado em Geografia. FFLCH/USP. 1999. 320 p.

FISCHER, M. L. Levantamento do gênero loxosceles Heinecken \& Lowe, 1832 no município de Curitiba, Paraná, Brasil. In: Estudos de Biologia, PUC/PR, vol.3 n. $038,1994$. 
FISCHER, M. L. Utilização do habitat por Loxosceles Intermedia MelloLeitão, 1934 e Loxosceles Laeta (Nicolet, 1849) no município de Curitiba, PR.: Uma abordagem experimental sobre aspectos ecológicos e comportamentais. Tese de Doutorado em Zoologia, UFPR, 2002.

FISCHER, M. L.; VASCONCELLOS-NETO, J. Determination of the maximun and minimum lethal temperatures $\left(\mathrm{LT}_{50}\right)$ for Loxosceles Intermedia Mello-Leitão, 1934 e Loxosceles Laeta (Nicolet, 1849) (Araneae, Sicariidae). In: Journal of Thermal Biology. n० 28, 2003. p. $563-570$.

GERTSCH, W. J. The Spider Genus Loxosceles in South America (Araneae, Scytididae). In: Bulletin of the American Museum of Natural History. New York: 1967. Vol. 136. Art. 3. $121-170$.

LEMOS, J. C.; LIMA, S. C., A Geografia Média e as Doenças Infecto-Parasitárias. Caminhos de Geografia, Uberlândia, 3(6), jun/2002.

MENDONÇA, F. Aspectos da Interação Clima-Ambiente-Saúde Humana: Da Relação Sociedade-Natureza à (in)sustentabilidade Ambiental. In: RA'EGA - O Espaço Geográfico em Análise, Curitiba, no 4, ano IV, 2000. p. 85 - 100.

MENDONÇA, F. Clima e Criminalidade: Ensaio analítico da Correlação entre Temperatura do Ar e a Incidência da Criminalidade Urbana. Curitiba: UFPR, 2001. 182p.

NATAL, D. Fundamentos de Saúde Pública. In: PHILLIPI JR, A. (et al.) Curso de Gestão Ambiental. Barueri/SP: Manoele, 2004. $1^{\text {a }}$ edição. p. 332 - 402.

NOGAROLLI, M. Evolução Climática do Estado do Paraná: 1970 - 1999. Dissertação de mestrado em Geografia, UFPR, 2007.

TRENTINI, R. P. Histórico do Loxoscelismo e sua ocorrência no município de Curitiba - Paraná, Monografia de Especialização em Análise Ambiental, Curso de Pós-Graduação em Geografia, UFPR, 2002.

TRENTINI, R. P. Fatores antrópicos-ambientais determinantes para o aumento de acidentes loxoscélicos no município de Curitiba-Paraná, Dissertação de Mestrado em Geografia, UFPR, 2005.

VETORELLO, M. L. A Influência da Temperatura, Umidade Relativa do Ar e Radiação Solar na Incidência dos Acidentes Loxoscélicos em Curitiba, Paraná, Brasil, no período de 1998 a 2001. Monografia de Especialização, Departamento de Epidemiologia, UFPR, 2002. 